Original Research Paper

\title{
Production of High-Performance Silica Fume Concrete
}

\author{
Omar Asad Ahmad \\ Department of Civil Engineering, Faculty of Engineering Technology, \\ Zarqa University, 132222, Zarqa, 13132, Jordan
}

Article history

Received: 19-09-2017

Revised: 13-11-2017

Accepted: 22-11-2017

Corresponding Author: Email: oahmad@zu.edu.jo

\begin{abstract}
This research aimed to produce concrete that will decrease disadvantages of portland concrete and resolve it. Mixture of Silica fume with concrete in this paper shows that the strength and hardness are increased. In this research the main gools is to compare the deference of compressive strength between standred concrete and concrete with silica fume with different additives ratio and to explore its effect on the main physical properiets of concrete. To achieve our goals in this research about 180 samples prepared to examened it's compressive strength, all concrete sample has the same mixing ratio and distributing to standard and Silica fume added by the volume $(5,10,15,20$ and $30 \%)$. The results show that the recommended addition was $15 \%$ of Silica fumes for optimum compressive strength that reaches $74.8 \mathrm{MPa}$. Also the economy of mixture compare to the market prices makes silica excellent to use as addition filler to concrete.
\end{abstract}

Keywords: Silica, Hardness, Cracks, Concrete, Aditives, Compressive Strength

\section{Introduction}

To helpmate the increasing request for sustainability, researchers have shown that the utilization of industrial by-products improves various properties of concrete and produces new materials. (Sobolev et al., 2009). Using mineral additives such as silica fume will enhance concrete strength and durability, because of their fine particles as shown in Fig. 2, large surface area and high $\mathrm{SiO}_{2}$ content. They fill the voids in the cement paste. Since Silica fume smaller than cement, it can fill the pores in cement paste resulting in denser and more impermeable texture (Maheswaran et al., 2013).

Concrete mainly consists of cement, different aggregates and water which mixed together. Admixtures added sometimes to change some of concrete properties. It is a vastly used construction material because of its ease of construction, Low cost of its Ingredients, Its good durability (Mehta and Monteiro, 1993). The strength of concrete is the major way to describe the properties of hardened concrete as compressive strength. Strength usually is a fundamental key of the quality of concrete because it is united to the structure of cement paste (Mehta and Monteiro, 1993). There are some factors affecting strength such as Water/Cement Ratio, Curing Time, Cement and Aggregate. Since the W/C ratio controls the porosity of concrete, it controls the strength as well. Therefore, in practice, we can assure the strength of properly compacted concrete at a given age by specifying the $\mathrm{W} / \mathrm{C}$ ratio. It is usually wise to use as low water content as possible, since the more water added to concrete mix the higher the porosity regardless the fact that the $\mathrm{w} / \mathrm{c}$ ratio is being kept constant. The relevance between W/C ratio and strength is shown in Fig. 1.

The mixing procedure essentialy consists of stirring, the objective being to coat the surface of all aggregate particles with cement paste and to blend all the ingredients of concrete into a uniform mass. The main type of mixer is a batch mixer, which means that one batch of concrete is mixed and discharged before any more materials are put into the mixer (Kosmatka and Panarese, 1994; Ahmad and Awwa, 2014).

Silica fume, is an amorphous polymorph of silicon dioxide, silica. The major field of usage is as pozzolanic material for high performance concrete (SFA, 2011).

It is sometimes confused with fumed silica. However, the production process, particle characteristics and fields of application of fumed silica are all different from those of silica fume (SFA, 2011).

Because of its extreme fineness and high silica content, silica fume is a very effective pozzolanic material. Standard specifications for silica fume used in cementious mixtures are ASTM C1240, EN 13263 (ASTM C511).

Silica fume is added to concrete to improve its properties both the mechanical improvements resulting from addition of a very fine powder as well as from the reactions between the silica fume and free calcium hydroxide in the paste (Ahmad and Awwad, 2014; Detwiler and Mehta, 1989). 


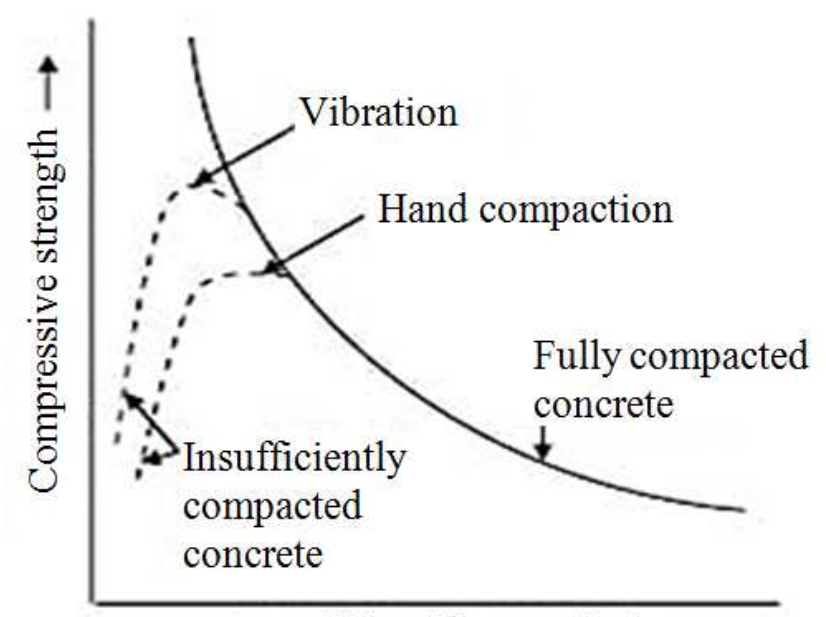

Water/Cement Ratio $\longrightarrow$

Fig. 1: Relevance between W/C ratio and strength

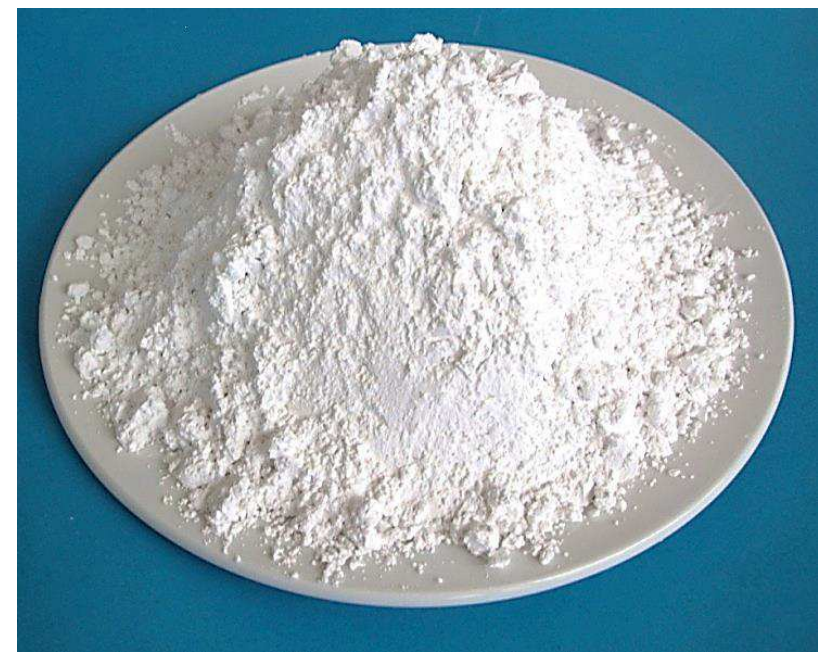

Fig. 2: Silica fume

Addition of silica fume also reduces the permeability of concrete to chloride ions, which protects the reinforcing steel of concrete from corrosion, especially in chloride-rich environments. (ASTM C511; Detwiler and Mehta, 1989; Awwad and Ahmad, 2017)

Silica fume reduces bleeding significantly, also blocks the pores in the fresh concrete so water within the concrete is not allowed to come to the surface (Bs1881: part 116: 1983; Neville and Brooks, 2010).

Zaki and Ragab (2009) conducted testing using nano silica in concrete and concluded the optimum amount of nano silica was $0.5 \%$ by weight of cementitious material. Gopinath et al. (2012) investigated the effects of nano silica in normal strength concrete using 1.5 and $3 \%$ of nano silica to cement replacement by weight. Salkhordeh et al. (2011) investigated the effects of recycled concrete as an aggregate and nano silica as cement replacement in Self-
Consolidating Concrete (SCC) and found that adding nano silica lead to an increase in compressive strength.

The fundamental objective of this research was to provide information about the hardened properties of concrete achieved by using local silica fume materials in Jordan to facilitate the introduction of Silica Fume Concrete (SFC) technology into general construction practice. Also Investigate the effect of silica fume in SFC mixtures and on materials properties such as compressive strength. Also to investigate the viability use of Silica fume to reduce early cracking and inhibit later crack growth.

\section{Materials and Methods}

63 micron Silica was provided from ISICInternational Silica Industries Co (ACI Committee 226, 1987). The prefixes of this silica are in the Table 1. 
Table 1: Silica fumes physical and chemical properties

\section{Bulk density}

Oil absorption

$\mathrm{PH}$

Hardness

Minimum brightness

$\mathrm{SiO}_{2}$

$\mathrm{Fe}_{2} \mathrm{O}_{3}$

$\mathrm{Al}_{2} \mathrm{O}_{3}$

$\mathrm{TiO}_{2}$

$0.82 \mathrm{~g} / \mathrm{m}^{3}$
$26 \mathrm{~g} / 100 \mathrm{~g}$
7
7 Moh's
90
$98.8-99.1 \%$
$0.025-0.04 \%$
$0.50-1.00 \%$
$0.04-0.09 \%$

This grade of micronized silica flour is manufactured from super fine silica sand having a $\mathrm{SiO}_{2}$ content of up to $99 \%$.

High performance concrete superplasticizer (formerly known as Flocrete PC200) was provided from Ayla Construction Chemicals Company . Hyperplast PC200 is a high performance super plasticizing admixture based on polycarboxylic polymers with long specially designed to enable the water content of the concrete to perform more effectively. This effect can be used in high strength concrete and flowable concrete mixes, to achieve highest concrete durability and performance (ASTM C1240).

Hyperplast PC200 complies with ASTEM C494, type A and G, depending in dosage use Hyperplast PC200 should be added to the concrete with the mixing water to achieve optimum performance.

Local aggregate which used in this research is from Jordan Modern Ready Mix Concrete-Mnaseer Group. Aggregates typically constitute $75 \%$ of concrete volume. Hence, aggregate types and sizes play an essential role in modifying the concrete properties as noted in the previous section (Mehta and Monteiro, 1993).

Grain size distribution according to ASTM C 136-01 a standard test method for Sieve analysis of fine and coarse aggregates (ASTM C 136-01a). Table 2 shows grading of coarse aggregate.

According to ASTM C127-88, Standard Test Method for Specific Gravity and Absorption of Coarse Aggregate (ASTM standards: C 127-88).

Table 3 and 4 show the result of weights and specific gravities of aggregates.

Specific gravity of fine aggregate was performed according to ASTM C128-97, standard test method for specific gravity and water absorption of fine aggregate (ASTM standards: C 128-97) and shown in Table 5 and 6.

Determination of Aggregate Impact Value (AIV) was performed according to ASTM standards: C 131-96, Standard test method for resistance to degradation of small - size coarse aggregate and shown in Table 7. (ASTM standards: C 131-96).

Los Angeles Test was performed according According to ASTM C131 - 96, Standard Test Method for Resistance to Degradation of Small-Size Coarse Aggregate (ASTM standards: C 131-96)

By Abrasion and Impact in the Los Angeles Machine the result shown in Table 8.
Table 2: Grading of aggregates

\begin{tabular}{lrrr}
\hline Sieve size $(\mathrm{mm})$ & Coarse & Medium & Fine \\
\hline 37.30 & 100.0 & 100.0 & 100.0 \\
25.40 & 100.0 & 100.0 & 100.0 \\
19.00 & 62.1 & 100.0 & 100.0 \\
9.530 & 1.0 & 35.2 & 100.0 \\
4.750 & 0.9 & 3.3 & 98.4 \\
2.360 & 0.8 & 3.0 & 97.5 \\
1.180 & 0.8 & 2.7 & 90.5 \\
0.600 & 0.8 & 2.2 & 71.2 \\
0.300 & 0.7 & 1.6 & 13.5 \\
0.150 & 0.7 & 1.1 & 4.1 \\
0.075 & 0.5 & 0.8 & 2.7 \\
\hline
\end{tabular}

Table 3: Specific Gravity testing result of coarse and medium aggregates

\begin{tabular}{llll}
\hline & Symbol & $\begin{array}{l}\text { Weight }(\mathrm{g}) \\
\text { of coarse } \\
\text { aggregate }\end{array}$ & $\begin{array}{l}\text { Weight } \\
\text { (g) of } \\
\text { medium }\end{array}$ \\
\hline $\begin{array}{l}\text { Description } \\
\text { Weight of }\end{array}$ & Wd sample & 966.5 & 1131 \\
$\begin{array}{l}\text { Weight of standard } \\
\text { surface dry sample }\end{array}$ & Wssd & 984.0 & 1145 \\
$\begin{array}{l}\text { Weight of } \\
\text { submerged sample }\end{array}$ & Wsub & 619.3 & 717.2 \\
$\begin{array}{l}\text { Dry volume } \\
\begin{array}{l}\text { Volume of standard } \\
\text { Surface dry sample }\end{array}\end{array}$ & Vd & 347.2 & 413.8 \\
\hline
\end{tabular}

Table 4: Water absorption of coarse and medium aggregates

\begin{tabular}{llll}
\hline Description & Symbol & coarse & meduim \\
\hline $\begin{array}{l}\text { Apparent specific } \\
\text { gravity }\end{array}$ & Gaap & 2.78 & 2.73 \\
$\begin{array}{l}\text { Bulk specific gravity } \\
\text { Water absorption }\end{array}$ & Gbulk & 2.65 & 2.64 \\
\hline
\end{tabular}

Table 5: Water Absorption of sand

\begin{tabular}{lll}
\hline Description & Symbol & fine \\
\hline Apparent specific gravity & Gaap & 2.48 \\
Bulk specific gravity & Gbulk & 2.38 \\
Water absorption & Abs & $1.65 \%$ \\
\hline
\end{tabular}

Table 6: Test result for Specific gravity of fine aggregate

\begin{tabular}{lll}
\hline Description & Symbol & $\begin{array}{l}\text { Weight }(\mathrm{g}) \text { of } \\
\text { fine aggregate }\end{array}$ \\
\hline $\begin{array}{l}\text { Weight of dry sample } \\
\begin{array}{l}\text { Weight of standard } \\
\text { surface dry sample }\end{array}\end{array}$ & Wd & 290.2 \\
$\begin{array}{l}\text { Volume of standard } \\
\begin{array}{l}\text { Surface dry sample } \\
\text { Dry volume }\end{array}\end{array}$ & Vssd & 295.0 \\
\hline
\end{tabular}

High density concrete mixture was made with ordinary Portland cement (OPC), with different fractions of Silica fume. In mixing concrete the mixer which use is Batch Mixers. Two main types of batch mixer can be distinguished by the orientation of the axis of rotation: horizontal or inclined (drum mixers) or vertical (pan mixers) (Kosmatka and Panarese, 1994). 
Table 7: Tow samples results of Impact Value I.V

\begin{tabular}{lcc}
\hline Description & $\begin{array}{c}\text { Weight of } \\
\text { first sample }\end{array}$ & $\begin{array}{l}\text { Weight of } \\
\text { second sample }\end{array}$ \\
\hline Weight of empty can & 615.4 & 615.40 \\
Weight of can + sample & 916.0 & 907.20 \\
Sample weight & 300.6 & 291.80 \\
Weight of sample & 264.7 & 264.50 \\
retained on sieve & & \\
Weight of sample pass & 35.90 & 45.30 \\
from sieve $(2.36 \mathrm{~mm})$ & & \\
Impact value & 11.94 & 15.52 \\
\hline A
\end{tabular}

Average of two trials is equal to $=13.73 \%$

Table 8: Results of L.A experiment

\begin{tabular}{lll}
\hline Description & Symbol & Weight $(\mathrm{g})$ \\
\hline $\begin{array}{l}\text { Total weight of sample } \\
\text { Weight of sample retain }\end{array}$ & W1 & 5000 \\
$\begin{array}{l}\text { on No.12 sieve } \\
\text { Percent of abrasion }\end{array}$ & W2 & 3742 \\
\hline
\end{tabular}

Table 9: Component weights for 1cu.m for the mixture

\begin{tabular}{ll}
\hline Type of material & Weight $\left(\mathrm{Kg} / \mathrm{m}^{3}\right)$ \\
\hline Cement & 370 \\
Coarse aggregate & 296 \\
Fine aggregate & 888 \\
Sand & 592 \\
Silica & $(5,10,15,20,30) \%$ \\
Water & 111 \\
W/C ratio & 0.3 \\
\hline
\end{tabular}

Table 10: Silica Addition weight for each percent

\begin{tabular}{lc}
\hline Silica Percent $(\%)$ & Weight $\left(\mathrm{Kg} / \mathrm{m}^{3}\right)$ \\
\hline 5 & 18.5 \\
10 & 37.0 \\
15 & 55.5 \\
20 & 74.0 \\
30 & 111.0 \\
\hline
\end{tabular}

Silica fume was mixed with cement in L.A machine for 500 rounds with 11 steel balls to insure that silica mixed very well with concrete.

Hyper-plast added to the water with ratio $1.5 \%$ of cement weight. If a good workability during mixing was not established $0.5 \%$ Hyper-plast added. As the prefixes of hyper-plast the dosage should not exceed $2.5 \mathrm{~L} / 100 \mathrm{~kg}$ cement (Kosmatka and Panarese, 1994).

Mixing time is an important influence on the production of concrete at uniform composition. Initially dry material mixed for $5 \mathrm{~min}$ and finally adding water. After adding water and hyper-plast a mixing period of 15 min should be accomplish to insure good mixing. Pouring the concrete in cubes into three layers with compact each layer by 25 times for testing the hardened

concrete properties. And as noticed while working the produced mixture has a self-compaction behavior (Kosmatka and Panarese, 1994).

After casting, the concrete specimens were kept in the laboratory at room temperature for $24 \mathrm{~h}$. After that, they were placed in the water bath until the time of testing. Curing was performed in accordance with the ASTM C511 standard (ASTM C511).

The concrete mixes proportions were kept as (1.25:3:2) (cement: sand: aggregate) and added Silica Fume at $(5,10,15,20$ and 30 percent of cement weight.

Sand is divided into Sand and Stamp sand (2 for Sand and 1 for stamp sand).

Aggregate is divided into coarse and medium ( 0.7 for coarse, 1.3 for medium). Table 9 and 10 show components weights for one cubic meter of concrete and silica addition weight for each percent.

\section{Results and Discussion}

The properties of hardened concrete can be significantly improved by Silica fume.

As we said before the strength of concrete is the major way to describe the properties of hardened concrete as compressive.

Strength usually gives an overall picture of the quality of concrete because it is related to the structure of cement paste (Kosmatka and Panarese, 1994).

Compressive strength test on cubes According to Bs1881: part 116: 1983 [9-10] Method of determination of compressive strength of concrete cubes $\left(15^{*} 15^{*} 15 \mathrm{~cm}\right.$ in size). List of tables and figures represents compressive strength results of the concrete mixture. 180 samples was prepered for testing (averge of 5 samples for each test). Compressive strength result on testing cubes are shown in Table 11 and Fig. 3.

The addition of silica fume i.e. $10 \%$ actually increases the 28 days compressive strength by about $(12.85 \%)$ and when the volumes of silica fume reaches $15 \%$ then the compressive strength increased $(18.52 \%)$ which is optimum strength.

Otherwise, the addition of silica fume at rates of 20 and 30 percent decreases the 28 days strength by about (14) and (18.3\%) respectively.

Unexpected behavior of the addition of silica fumes at rate of 5\% which gives an inverse curve. That effects the chemical reaction of pure silica fume with water $\left(\mathrm{Si}_{2} \mathrm{O}_{4} \cdot \mathrm{nH}_{2} \mathrm{O}\right)$ then water get higher that leads to decrease 14 and 21 days to be less than 7 and 28 days which represent in Fig. 3.

The results in Table 11 seem to indicate that there may be an effective volume threshold for adversely affecting the compressive strength of concrete that is exceeded at $15 \%$.

All things considered, it appears that at dosage rates ( 0.1 and 0.15 the addition of Silica fume) does not significantly detract from and even improve the compressive strength.

Higher dosage rates $(0.20$ and 0.30 the addition of Silica fume) however decrease the strength of concrete matrix due to higher volumes of Silica Fume interfering with the cohesiveness of the concrete matrix (ACI 234R06, 2013; EN 13263). 
Table 11: Compressive strength results

\begin{tabular}{|c|c|c|c|c|}
\hline \multirow{2}{*}{$\begin{array}{l}\text { Percent of silica fume } \\
\text { (by volume) }(\%)\end{array}$} & \multicolumn{4}{|c|}{ Strength of concrete } \\
\hline & 7 days & 14 days & 21 days & 28 days \\
\hline 0 & 36.67 & 46.67 & 54.67 & 63.11 \\
\hline \multirow[t]{2}{*}{5} & 56.70 & 54.60 & 44.67 & 53.33 \\
\hline & 50.22 & 44.40 & 45.55 & 53.11 \\
\hline Avg. 5 & 53.46 & 49.50 & 45.11 & 53.22 \\
\hline 10 & 58.00 & 62.67 & 66.44 & 70.22 \\
\hline 15 & 56.66 & 64.22 & 68.89 & 74.88 \\
\hline 20 & 40.00 & 49.56 & 52.44 & 54.22 \\
\hline 30 & 34.44 & 38.00 & 46.22 & 51.56 \\
\hline
\end{tabular}

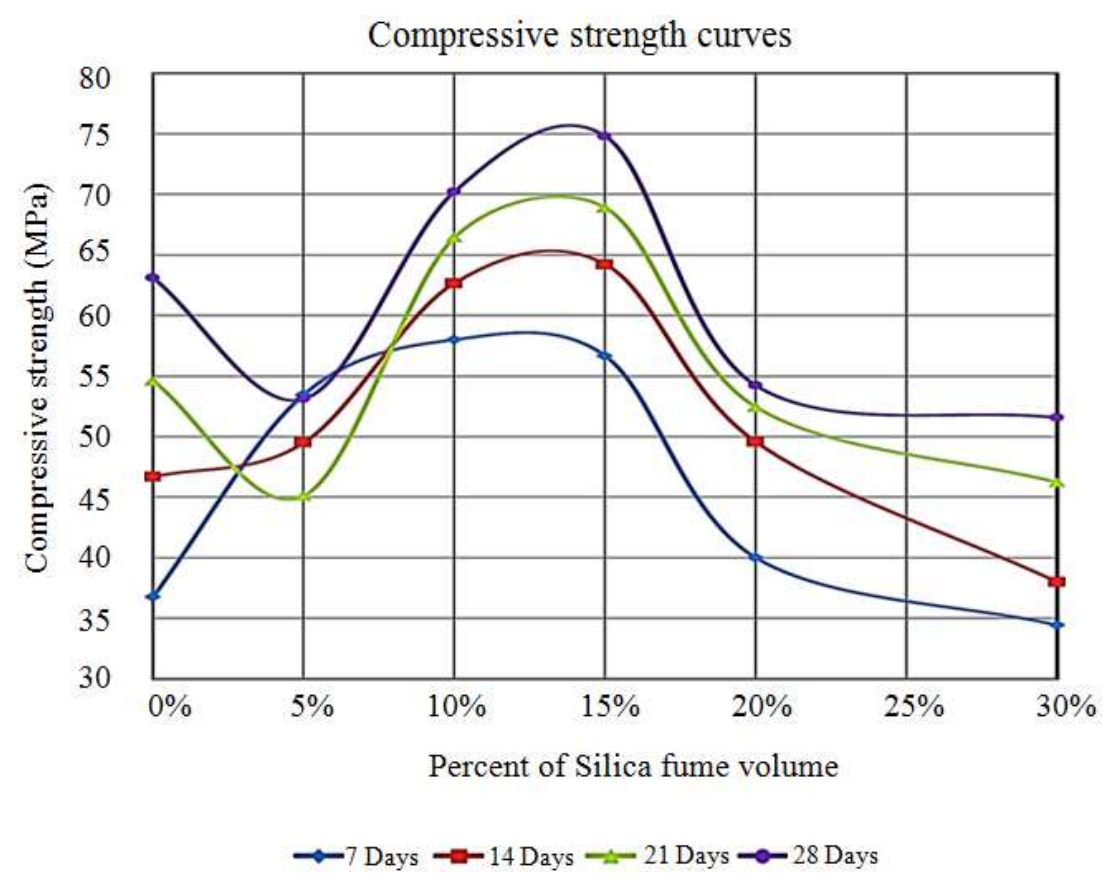

Fig. 3: Graphical representations for Compressive strength test result

The graphical representation of the tests results is given in Fig. 3.

Maheswaran et al. (2013) indicated that the reaction of Nano-Silica with excess $\mathrm{CH}$ during cement hydration has led to reduction in calcium hydroxide content and thus resulted in reduction in chemical leaching of $\mathrm{CH}$ and sulfate attack and enhancement of the delay in development of micro crack. The physical effect results because Nano-Silica is about 100 times smaller than cement. It can fill the voids in the cement paste resulting in denser and more impermeable texture of mortar. Ye Qing et al. (2007; Bagheri et al., 2013) reported that the compressive strength increases with the increase in replacement $5 \%$ by mass. Jonbi et al. (2012) reported that adding Nano-Silica with 5\% replacing of cement by weight showed higher compressive strength up to 28 days.

Cost considered as one of the most important part of any project which plays an important role ensuring the economic success of the project. So, we're going to demonstrate a Cost-Benefit Analysis of Silica fume additions to the concrete and whether we will get any benefit from Silica fume or not. This study includes pricing concrete and Silica fume and changing in the physical properties of concrete after different additions of Silica fume.

Concrete price classified depending on the compressive strength, the higher the strength the higher the price and it changes from a day to another, nowadays concrete price of one cubic meter for strength of 30,60 , $65,70,75 \mathrm{MPa}$ are 55, 75, 78, 85, $90 \mathrm{JD}$ respectively.

Silica fume is priced in accordance with weight, one kilograms of Silica fume is about 0.07 JD. Quantity of Silica fume added to the concrete increasing the price of concrete according for its price. We will focus on percent of silica fume which gives a certain compressive strength. Plain concrete coast and Cost of Silica fume addition are shown in Table 12 and 13 respectivlly. 
Table 12: Plain concrete coast

\begin{tabular}{llc}
\hline Strength 63 MPa & & \\
\hline---1 & & \\
Type of material & Weight $\left(\mathrm{Kg} / \mathrm{m}^{3}\right)$ & Cost $(\mathrm{JD})$ \\
\hline Cement & 370 & 33.300 \\
Coarse Aggregate & 888 & 3.940 \\
Fine Aggregate & 197 & 0.815 \\
Sand & 592 & 0.550 \\
Water & 111 & 3.330 \\
Total coast & --- & 42.000 \\
\hline
\end{tabular}

Table 13: Cost of Silica fume addition to concrete

\begin{tabular}{lrr}
\hline Strength $(\mathrm{MPa})$ & 70.00 & 75.0 \\
Percent of Silica fume $(\%)$ & 10.00 & 15.0 \\
Weight $(\mathrm{Kg})$ for $1 \mathrm{~m}^{3}$ & 37.00 & 55.5 \\
Price of Silica fume & 2.59 & 3.85 \\
Price of Whole mixture $\left(\mathrm{JD} / \mathrm{m}^{3}\right)$ & 44.59 & 45.85 \\
\hline
\end{tabular}

Table 14: Percentage increasing in compressive strength.

\begin{tabular}{|c|c|c|c|}
\hline $\begin{array}{l}\text { Silica } \\
\text { percent } \\
(\%) \\
\end{array}$ & $\begin{array}{l}\text { Compressive } \\
\text { Strength } \\
\text { without Silica } \\
\text { fume }\end{array}$ & $\begin{array}{l}\text { Compressive } \\
\text { strength } \\
\text { with silica } \\
\text { fume }\end{array}$ & $\begin{array}{l}\text { Increasing } \\
(\%)\end{array}$ \\
\hline 10 & $63.11 \mathrm{MPa}$ & $71.22 \mathrm{MPa}$ & 12.85 \\
\hline 15 & $63.11 \mathrm{MPa}$ & $74.88 \mathrm{MPa}$ & 18.52 \\
\hline
\end{tabular}

The uses for silica fume in concrete fit into the general categories of enhancing mechanical properties, improving durability, enhancing constructability.

A special use of silica fume is the production of highperformance concrete bridges where the strength and durability properties of the concrete are critical. This use of silica fume is also described (ACI 234R-06, 2013; UM, 2014).

Although increasing concrete strength using silica fume has gained the most attention, more silica fume has actually been used in applications where increased durability is the driving factor. For the purposes of this presentation, the uses of silica fume have been divided into distinct categories. It should be remembered that adding silica fume will affect all concrete properties simultaneously. For example, reducing the permeability of concrete will usually increase the compressive strength of that concrete. The amount of increase will depend upon the concrete mixture selected. (ACI 234R-06, 2013; UM, 2014).

The most significant improvements can be seen in the compressive strength and modulus of elasticity. Initially, designers took advantage of increases in strength and modulus in high-rise structures. More recently, highstrength silica-fume concrete has been used in substructures of high-performance concrete bridges. The greatest use of silica fume has been in applications where improvements in durability have been the goal of the designer. Significant improvements can be seen in the permeability, abrasion resistance and chemical resistance of concrete (ACI 234R-06, 2013).
Contractors can take advantage of the properties of silica fume concrete to expedite projects or to achieve properties that might otherwise be impossible to achieve. Don't forget that using silica fume in this role will also improve the mechanical and durability properties of the concrete as well as enhance the constructability. The results indicate that incorporation of Silica Fume in concrete can increase compressive strength and improve many properties of concrete. The increase is dependent on the fines of silica fume. The results on our research were good, which increased the compressive strength as shown in Table 14 (ACI 234R-06, 2013).

From our benefit cost study we can summarize the advantages of using silica fume as addition to concrete:

- Silica fume enhance the compressive strength, shear strength and reduce permeability of concrete

- With silica fume the voids are minimized which leads to reduce the weak-points in the concrete and to increase strength

- Cracks are reduced when using silica fume because it works as filler and consume water not needed for concrete to complete its reaction (ASTM C786/C786M - 10)

- Increasing durability by preventing the environment attracts

- $\quad$ Reducing the maintenance cost by reducing cracks

- The economical of using silica fume to produce high performance concrete makes it good to use in concrete

Intisar et al. (2016) reported that compressive strength of cement paste increased with the increase of Nano-Silica in cement paste up to $5 \%$, further increase in percentages of Nano Silica didn't show further improvement in compressive strength. Justin et al. (2016) reported that nano silica in all percentages of cement replacements showed a significant increase in compressive strength in all ages of testing.

\section{Conclusion}

From this research the following conclusion have been established:

1. Silica Fume Concrete (SFC) is a high strength mixture of aggregates, cement, water and hyper-plast

2. SFC is used to manufacture high strength sectioned

3. The particle size of silica fume should not be larger than cement particle (less than 75 micron)

4. After the cost study we improved that adding silica fume to concrete improve its properties also much economically comparing with market prices with the benefits we gain

5. Normal compressive strength for plane concrete $63.11 \mathrm{MPa}$ 
6. Adding $10 \%$ silica fume increases compressive strength at 7, 14, 21 and 28 days by $58.1,34.28,21.5$ and $11.26 \%$ respectively which reaches $71.22 \mathrm{MPa}$

7. Adding $15 \%$ silica fume increases compressive strength at 7, 14, 21 and 28 days by 54.6, 37.6, 26 and $18.65 \%$ respectively which reaches $74.88 \mathrm{MPa}$

8. Optimum strength as shown before is almost 75 $\mathrm{MPa}$ which can be reached when adding $15 \%$ of silica fume on the mixture

9. Increasing percentage of silica fume in concrete will reduce the strength of concrete and consume much water than needed at low rates

10. Silica fume must be uniformly distributed with cement before mixing

\section{Acknowledgement}

The author wish to acknowledge the support of the Faculty of Engineering Technology-Zarqa University for providing the facilities to carry out this research.

\section{Funding Information}

This research is funded by the Deanship of Research and Graduate Studies in Zarqa University/Jordan-Zarqa.

\section{Ethics}

This article is original and contains unpublished material. The corresponding author confirms that all of the other authors have read and approved the manuscript and no ethical issues involved.

\section{References}

ASTM C786 / C786M - 10. Standard test method for fineness of cement and raw materials by the 300 -

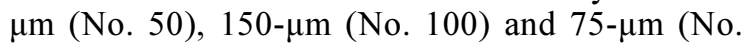
200) Sieves.

Bs1881: part 116, 1983. Method of determination of compressive strength of concrete cubes.

ACI 234R-06, 2013. Guide to silica fume in concrete. American Concrete Institute.

ACI Committee 226, 1987. Silica fume in concrete: Preliminary report. ACI Materials J.

Ahmad, O.A. and M. Awwad, 2014. The effects of polypropylene fibers additions on compressive and tensile strengths of concrete. Int. J. Civil Environ. Eng., 37: 1365-1372.

ASTM C 136-01a. Standard test method "Sieve analysis of fine and coarse aggregates".

ASTM C1240. Standard specification for silica fume used in cementitious mixtures.

ASTM C511. Standard test method for fineness of cement and raw materials.

ASTM standards: C 127-88. Standard test method for specific gravity and absorption of coarse aggregate.
ASTM standards: C 128-97. Standard test method for specific gravity and absorption of fine aggregate.

ASTM standards: C 131-96. Standard test method for resistance to degradation of small-size coarse aggregate.

Awwad, M.T. and O.A. Ahmad, 2017. Effects of different environments on reinforcement concrete corrosion. Am. J. Environ. Sci., 13: 307-314. DOI: 10.3844/ajessp.2017.307.314

Bagheri, A., H. Zanganeh, H. Alizaden, M. Shakerinian and M. Marian, 2013. Comparing the performance of fine fly ash and silica fume in enhancing the properties of concretes containing fly ash. Construct. Build. Mater., 47: 1402-14082.

Detwiler, R.J. and P.K. Mehta, 1989. Chemical and physical effects of silica fume on the mechanical behavior of concrete. Materials J., 86: 609-614.

EN 13263. Silica fume for concrete. http://www.cen.eu

Gopinath, S., P.C. Mouli, A. Murthy, N. Iyer and S. Maheswaran, 2012. Effect of nano silica on mechanical properties and durability of normal strength concrete. Archives Civil Eng., 58: 433-444. DOI: $10.2478 / \mathrm{v} .10169-012-0023-y$

Intisar, K., T.M. Abu-Lebdeh, E.H. Fini and S.A. Hamoush, 2016. The use of nano Silica for improving mechanical properties of hardened cement paste. Am. J. Eng. Applied Sci. 2016: 146.154. DOI: 10.3844/ajeassp.2016.146.154

Jonbi, I. Pane, B. Hariandja and I. Imran, 2012. The use of nanosilica for improving of concrete compressive strength and durability. Applied Mechan. Mater., 204-208: 4059-4062.

DOI: $\quad$ 10.4028/www.scientific.net/AMM.204208.4059

Justin, M., T.M. Abu-Lebdeh, S.A. Hamoush and M. Picornell, 2016. Effect of nano Silica on the compressive strength of harden cement paste at different stages of hydration. Am. J. Eng. Applied Sci., 9: 166-177. DOI: 10.3844/ajeassp.2016.166.177

Kosmatka, S.H. and B. Panarese, 1994. Design and Control of Concrete Mixtures. 1st Edn., Portland Cement Association, Skokie, Illinois, USA.

Maheswaran, S., B. Bhuvaneshwari, G.S. Palani, R. Nagesh and S. Kalaiselvam, 2013. An overview on the influence of nano-silica in concrete and a research initiative. Res. J. Recent Sci., 2: 17-24.

Mehta, P.K. and P.J.M. Monteiro, 1993. Concrete: Structure, Properties and Materials. 2nd Edn., Prentice-Hall, Inc. Englewood Cliffs, NJ., ISBN-10: 0131756214 , pp: 548.

Neville, A.M. and J.J. Brooks, 2010. 2nd Edn., Concrete Technology.

Salkhordeh, S., P. Golbazi and H. Amini, 2011. The improvement of 28-day compressive strength of SCC made by different percentages of recycled concrete aggregates using nano-silica. 
SFA, 2011. Silica fume user's manual. Silica Fume Association.

Sobolev, K., I. Flores, L.M, Torres-Martinez, P.L. Valdez and P.L. Zarazua et al., 2009. Engineering of $\mathrm{SiO} 2$ nanoparticles for optimal performance in nano cement-based materials. Nanotechnol. Construct., 3: 139-148. DOI: 10.1007/978-3-642-00980-8 18

UM, 2014. Fly Ash, Slag, Silica Fume and Natural Pozzolans. Chapter 3, The University of Memphis, USA.
Ye Qing, Y., Z. Zenan, K. Deyu and C. Rongshen, 2007. Influence of nano-SiO2 addition on properties of hardened cement paste as compared with silica fume. Construct. Build. Mater., 21: 539-545.

DOI: 10.1016/j.conbuildmat.2005.09.001

Zaki, I. and K. Ragab, 2009. How nanotechnology can change concrete industry. Proceedings of the International Conference Sustainable Built Environment Infrastructures in Developing Countries, (IDC'09), pp: 2170-0095. 